\title{
Perspektif Tenaga Kesehatan: Budaya Keselamatan Pasien pada Puskesmas PONED di Kota Bandung
}

\author{
Reisia Palmina Brahmana ${ }^{1}$, Kurnia Wahyudi², Lukman Hilfi \\ ${ }^{1}$ Fakultas Kedokteran Universitas Padjadjaran \\ ${ }^{2}$ Departemen Ilmu Kesehatan Masyarakat, Fakultas Kedokteran Universitas Padjadjaran
}

\begin{abstract}
Abstrak
Kejadian Tidak Diharapkan (KTD) yang paling umum terjadi saat persalinan adalah infeksi. Hal ini seringkali disebabkan oleh faktor pelayanan kesehatan, baik pelayanan kesehatan di rumah sakit maupun di Puskesmas Pelayanan Obstetri Neonatal Emergensi Dasar (PONED). Penelitian ini bertujuan untuk mengetahui gambaran budaya keselamatan pasien pada Puskesmas PONED di Kota Bandung. Penelitian ini menggunakan metode deskriptif kuantitatif dengan desain potong lintang yaitu dengan menggunakan data primer dari kuesioner. Penelitian dilakukan di Puskesmas Ibrahim Adjie dan Puskesmas Garuda pada bulan April hingga Juni 2017. Subjek penelitian adalah tenaga kesehatan di Puskesmas PONED, yaitu 53 responden. Kriteria inklusi adalah tenaga kesehatan Puskesmas PONED yaitu, dokter umum; dokter gigi; perawat; perawat gigi; bidan; apoteker; kepala puskesmas; dan nutrisionis yang bersedia mengisi kuesioner dan pegawai yang berada di puskesmas tersebut ketika kuisioner dibagikan. Hasil penelitian menunjukkan bahwa terdapat tiga indikator budaya keselamatan pasien dalam kategori kuat, enam indikator dalam kategori sedang dan tiga indikator yang dalam kategori lemah. Simpulan penelitian adalah budaya keselamatan pasien pada Puskesmas PONED di Kota Bandung ada dalam kategori sedang. Perlu dibuat alat ukur untuk menilai budaya keselamatan pasien di Puskesmas PONED.
\end{abstract}

Kata Kunci : Budaya keselamatan pasien, PONED, Puskesmas.

\section{Health Workers Perspective: Patient Safety Culture in Puskesmas PONED in Bandung City}

\begin{abstract}
The most common adverse event in labour and delivery is infection. It is frequently caused by health care, whether health care in hospital or health care in Puskesmas Pelayanan Obstetri Neonatal Emergensi Dasar (PONED). The purpose of this research was to know the overview of patient safety culture in Puskesmas PONED in Bandung City. This research used descriptive method by using cross sectional design with primary data from questionnaire. The research was done in Puskesmas Ibrahim Adjie and Puskesmas Garuda in April until June 2017. The subjects were health workers who worked in Puskesmas PONED, which were 53 respondents. The Inclusion criterias were health worker in Puskesmas PONED which were doctor; dentist; nurse; dental; nurse; midwife; pharmacist; kepala puskesmas and; nutritionist that were willing to fill the questionnaire and health workers which were in that puskesmas, when the questionnaire were distributed. The results showed that there were three indicators which were in strong category, six indicators which were in moderate category and three indicators which were in weak category. The conclusion of this research was that the patient safety culture in Puskesmas PONED in Bandung City was in moderate category. Instrument to assess patient safety culture in Puskesmas PONED should been made.
\end{abstract}

Keywords : Patient safety culture, PONED, Puskesmas

Korespondensi:

Reisia Palmina Brahmana

Fakultas Kedokteran Universitas Padjadjaran

Jl. Raya Bandung-Sumedang KM 21 Jatinangor, Sumedang

Mobile : 081347742913

Email : reisia14001@unpad.ac.id 


\section{Pendahuluan}

Keselamatan pasien adalah dasar dari pelayanan kesehatan yang baik. ${ }^{1}$ Keselamatan pasien juga menjadi salah satu indikator dalam menilai akreditasi institusi pelayanan kesehatan, oleh karena itu keselamatan pasien sangatlah penting. ${ }^{2}$ Namun, jika ditinjau dari insiden keselamatan pasien, keselamatan pasien di berbagai tingkat pelayanan kesehatan masih buruk, baik secara global maupun nasional. ${ }^{3-7}$ Insiden keselamatan pasien merupakan kejadian tidak disengaja dan pada dasarnya dapat dicegah, yang mengakibatkan atau berpotensi mengakibatkan cedera pada pasien, terdiri atas Kejadian Tidak Diharapkan (KTD), Kejadian Nyaris Cedera (KNC), Kejadian Tidak Cedera (KTC) dan Keadaan Potensial Cedera (KPC). ${ }^{2}$

Berdasarkan laporan Departemen Kesehatan dan Kemasyarakatan Amerika pada tahun 2010, ditemukan bahwa 13,5\% dari hospitalized medicare beneficiaries atau orang yang pengobatannya dibiayai oleh pemerintah, mengalami KTD saat dirawat di rumah sakit, 1,5\% hospitalized medicare beneficiaries bahkan alami kejadian yang sebabkan kematian. ${ }^{3}$ Komite Keselamatan Pasien Rumah Sakit (KKPRS), melaporkan bahwa di Indonesia terdapat 103 laporan insiden keselamatan pasien pada tahun 2010 dan 34 laporan di tahun 2011 pada tri wulan I. ${ }^{4}$ Insiden keselamatan pasien yang tinggi juga ditemukan pada pelayanan kesehatan primer. $^{7}$ Pelayanan kesehatan primer di Spanyol memiliki prevalensi KTD sebesar 0,8\% pada tahun 2007 . Berdasarkan penelitian yang dilakukan oleh Adam dan Aranaz pada tahun 2004 dan 2009 di Spanyol, KTD yang paling sering terjadi di pelayanan kesehatan primer adalah KTD yang berhubungan dengan pemberian obat. ${ }^{7,8}$

Salah satu faktor yang memengaruhi insiden keselamatan pasien adalah budaya keselamatan pasien. ${ }^{9}$ Budaya keselamatan pasien merupakan produk dari nilai, sikap, persepsi, kompetensi, dan pola tingkah laku individu atau kelompok. ${ }^{10}$ Penelitian telah membuktikan bahwa meningkatnya budaya keselamatan pasien berhubungan dengan menurunya KTD dan bahkan berhubungan dengan angka kematian di unit rawat intensif.9, 11 WHO pada tahun 2011 menyatakan bahwa KTD yang paling umum terjadi ketika persalinan adalah infeksi. ${ }^{12}$ Hal ini seringkali disebabkan oleh faktor pelayanan kesehatan. Puskesmas Pelayanan Obstetri Neonatal Emergensi Dasar (PONED) merupakan pelayanan kesehatan primer yang melayani pertolongan persalinan, ${ }^{13}$ oleh karena itu budaya keselamatan pasien pada Puskesmas PONED sangatlah penting. Walaupun demikian, sepengetahuan peneliti belum ada penelitian mengenai budaya keselamatan pasien waupun tingkat insiden keselamatan pasien di Puskesmas PONED di Indonesia. Oleh karena itu, penelitian ini bertujuan untuk mengetahui gambaran budaya keselamatan pasien pada Puskesmas PONED di Kota Bandung.

\section{Metode}

Penelitian ini menggunakan metode deskriptif kuantitatif dengan desain potong lintang yaitu dengan menggunakan data primer dari hasil kuesioner pada April hingga Juni 2017 di UPT Puskesmas Ibrahim Adjie dan UPT Puskesmas Garuda. Penelitian ini telah memperoleh ijin etik yang dikeluarkan oleh Komite Etik FK Unpad dengan no: 300/UN6.C.10/PN/2017 pada tanggal 14 Maret 2017, surat rekomendasi penelitian dari Badan Kesatuan Bangsa dan Politik dengan No: 070/456/Bakesbangpol pada tanggal 23 Maret 2017, dan surat keterangan dari Dinas Kesehatan pemerintah Kota Bandung dengan No: 070/4326-Dinkes pada tanggal 27 Maret 2017.

Peneliti menggunakan total sampling dan besar sampel penelitian adalah seluruh subjek yang memenuhi kriteria pemilihan yaitu 53 orang. Populasi target adalah seluruh tenaga kesehatan di Puskesmas PONED di Kota Bandung, populasi terjangkau adalah tenaga kesehatan di UPT Puskesmas Ibrahim Adjie dan UPT Puskesmas Garuda, dan subjek penelitian sesuai dengan kriteria pemilihan. Kriteria inklusi penelitian ini adalah tenaga kesehatan Puskesmas PONED yaitu meliputi dokter umum; dokter gigi; perawat; perawat gigi; bidan; apoteker; kepala puskesmas; dan nutrisionis yang bersedia mengisi kuesioner dan pegawai yang berada di puskesmas tersebut ketika kuesioner dibagikan.

Kriteria eksklusi pada penelitian ini adalah pegawai yang bekerja kurang dari 1 tahun di puskesmas tersebut, kuesioner yang tidak diisi sama sekali atau hanya diisi bagian latar belakang informasi, dan kuesioner dengan jawaban yang sama pada setiap pertanyaan. Metode statistik yang digunakan adalah analisis deskriptif.

Instrumen penelitian yang digunakan adalah Kuesioner Hospital Survey on Patient Safety Culture (HSOPSC) ${ }^{14}$ yang dikeluarkan oleh Agency for Healthcare Research and Quality (AHRQ). Peneliti mennerjemahkan kuesioner tersebut kedalam bahasa Indonesia dan mengubah kata "rumah sakit" menjadi "puskesmas". Kuesioner HSOPSC menilai 12 indikator budaya keselamatan pasien dengan mengunakan skala Likert, yaitu dengan kategori sangat jarang/ sangat tidak setuju; jarang/ tidak setuju; netral/ 
kadang-kadang; sering/ setuju; dan selalu/ sangat setuju. Dua belas indikator budaya keselamatan pasien tersebut adalah kerja sama dalam suatu unit; harapan dan tindakan supervisor atau manajer dalam mempromosikan keselamatan pasien; pembelajaran yang terorganisir dan perkembangan yang berkelanjutan; dukungan manajemen dalam keselamatan pasien; persepsi keseluruhan tentang keselamatan pasien; komunikasi dan umpan balik terhadap kesalahan; keterbukaan dalam komunikasi; kerja sama antar unit; staffing; handoff dan transisi; respons tidak menghukum terhadap kesalahan; dan frekuensi pelaporan kejadian.

Kuesioner HSOPSC juga menilai jumlah laporan insiden keselamatan pasien yang diisi dan dikumpulkan oleh responden dalam satu tahun dan pendapat responden terhadap derajat keselamatan pasien di puskesmas tersebut. Laporan insiden keselamatan pasien dikategorikan menjadi tidak pernah, sedikit (1-5 laporan), sedang (6-20 laporan), dan banyak ( $\geq 21$ laporan).

Uji validitas dan reliabilitas terhadap kuesioner HSOPSC dilakukan terlebih dahulu pada pegawai kesehatan di Puskesmas Padasuka. Correlation coefficient test dan Cronbach's reliability test, dengan standar $r>0,3$ dan $\alpha>0,7$ dipakai sebagai metode uji validitas dan reliabilitas. Jawaban pertanyaan mengenai indikator budaya keselamatan pasien akan dikelompokan menjadi tiga kelompok respons yang dijelaskan lebih rinci pada tabel 1 .
Tabel 1 Kelompok jawaban responden

\begin{tabular}{|c|c|c|}
\hline No & $\begin{array}{c}\text { Kelompok } \\
\text { Respon }\end{array}$ & Jawaban Pertanyan \\
\hline \multirow[t]{2}{*}{1} & Positif & $\begin{array}{l}\text { - Setuju/ sering dan sangat } \\
\text { setuju/ selalu pada penyataan } \\
\text { positif }\end{array}$ \\
\hline & & $\begin{array}{l}\text { - Tidak setuju/jarang dan sangat } \\
\text { tidak setuju/ tidak pernah pada } \\
\text { penyataan negatif }\end{array}$ \\
\hline 2 & Netral & •Netral/ kadang-kadang \\
\hline \multirow[t]{2}{*}{3} & Negatif & $\begin{array}{l}\text { - Setuju/ sering dan sangat } \\
\text { setuju/ selalu pada penyataan } \\
\text { negatif }\end{array}$ \\
\hline & & $\begin{array}{l}\text {-Tidak setuju/ jarang dan sangat } \\
\text { tidak setuju/ tidak pernah pada } \\
\text { penyataan positif. }\end{array}$ \\
\hline $\begin{array}{r}\text { Kete } \\
\mathrm{R} \\
\mathrm{k} \\
\mathrm{R} \\
\mathrm{k} \\
\mathrm{R}\end{array}$ & $\begin{array}{l}\text { angan: } \\
\text { espons posit } \\
\text { selamatan } \\
\text { espons posi } \\
\text { selamatan } \\
\text { espons posit } \\
\text { selamatan }\end{array}$ & $\begin{array}{l}\text { if } \geq 75 \%=\text { Indikator budaya } \\
\text { asien kategori kuat. } \\
\text { if } 50 \%-75 \%=\text { Indikator budaya } \\
\text { asien kategori sedang. } \\
\text { if } \leq 50 \%=\text { Indikator budaya } \\
\text { asien kategori lemah. }\end{array}$ \\
\hline
\end{tabular}

\section{Hasil}

Terdapat 53 responden dari 65 jumlah total tenaga kesehatan. Lima orang dieksklusi pada UPT Puskesmas Garuda dan tujuh orang dieksklusi pada UPT Puskesmas Ibrahim Adjie.

Tabel 2 menunjukkan bahwa sebagian besar responden berprofesi sebagai bidan $(53 \%)$ dan memiliki masa kerja di UPT puskesmas Garuda/ Ibrahim Adjie selama 1-10 tahun.

Tabel 2 Jenis profesi dan masa kerja responden di UPT Puskesmas Garuda/ Ibrahim Adjie

\begin{tabular}{|c|c|c|c|c|c|c|}
\hline \multirow[b]{2}{*}{ Profesi } & \multicolumn{2}{|c|}{ Jumlah responden } & \multirow[b]{2}{*}{$\begin{array}{c}\text { Total } \\
(n=53)\end{array}$} & \multicolumn{3}{|c|}{$\begin{array}{l}\text { Masa Kerja di Puskesmas Garuda/ } \\
\text { Ibrahim Adjie }\end{array}$} \\
\hline & $\begin{array}{c}\text { Puskesmas } \\
\text { Garuda } \\
(\mathbf{n}=\mathbf{3 0})\end{array}$ & $\begin{array}{l}\text { Puskesmas } \\
\text { Ibrahim Adjie } \\
\quad(n=23)\end{array}$ & & $\begin{array}{c}1-10 \\
(n=45)\end{array}$ & $\begin{array}{l}11-20 \\
(n=6)\end{array}$ & $\begin{array}{l}\geq 21 \\
(n=2)\end{array}$ \\
\hline Dokter umum & 5 & 4 & $9(17)$ & 9 & 0 & 0 \\
\hline Dokter gigi & 3 & 1 & $4(8)$ & 4 & 0 & 0 \\
\hline Perawat & 6 & 1 & $7(13)$ & 7 & 0 & 0 \\
\hline Perawat gigi & 1 & 1 & $2(4)$ & 2 & 0 & 0 \\
\hline Bidan & 13 & 15 & $28(53)$ & 20 & 6 & 2 \\
\hline $\begin{array}{l}\text { Kepala } \\
\text { Puskesmas }\end{array}$ & 1 & 0 & $1(2)$ & 1 & 0 & 0 \\
\hline Apoteker & 1 & 0 & $1(2)$ & 1 & 0 & 0 \\
\hline Nutrisionis & 0 & 1 & $1(2)$ & 1 & 0 & 0 \\
\hline Total & 30 & 23 & $53(100)$ & 45 & 6 & 2 \\
\hline
\end{tabular}


Tabel 3 Indikator budaya keselamatan pasien pada Puskesmas PONED di Kota Bandung

\begin{tabular}{clcc}
\hline No & \multicolumn{1}{c}{ Indikator } & $\begin{array}{c}\text { Persentase } \\
\text { Respons positif (\%) }\end{array}$ & $\begin{array}{c}\text { Kategori } \\
\text { Budaya }\end{array}$ \\
\hline 1 & Harapan dan tindakan manajer dan supervisor dalam & 58 & Sedang \\
& mempromosikan keselamtan pasien & & \\
2 & Kerja sama dalam satu unit & 91 & Kuat \\
3 & Pembelajaran terorganisir dan perkembangan berkelanjutan & 94 & Kuat \\
4 & Keterbukaan dalam komunikasi & 53 & Sedang \\
5 & Unpam balik dan komunikasi tentang kesalahan & 62 & Sedang \\
6 & Respons tidak menghukum terhadap kesalahan & 45 & Lemah \\
7 & Staffing & 36 & Lemah \\
8 & Dukungan manajemen terhadap keselamatan pasien & 69 & Sedang \\
9 & Kerja sama antar unit & 85 & Kuat \\
10 & Handoff dan transisi & 65 & Sedang \\
11 & Persepsi keseluruhan terhadap keselamatan pasien & 61 & Sedang \\
12 & Frekuensi pelaporan kejadian & 45 & Lemah \\
\hline
\end{tabular}

Tabel 4 Jumlah laporan insiden keselamatan pasien yang diisi dan dikumpulkan oleh responden dalam satu tahun

\begin{tabular}{lccc}
\hline Kategori & $\begin{array}{l}\text { Puskesmas } \\
\text { Garuda } \\
\text { (n=30) }\end{array}$ & $\begin{array}{l}\text { Puskesmas } \\
\text { Ibrahim } \\
\text { Adjie } \\
\text { (n=23) }\end{array}$ & $\begin{array}{l}\text { Total } \\
\text { (n=53) }\end{array}$ \\
\hline $\begin{array}{l}\text { Tidak } \\
\text { pernah }\end{array}$ & 2 & 12 & 14 \\
$\begin{array}{l}\text { Sedikit (1-5 } \\
\text { laporan) }\end{array}$ & 19 & 11 & 30 \\
$\begin{array}{l}\text { Sedang (6- } \\
\text { 10 laporan) }\end{array}$ & 9 & 0 & 9 \\
$\begin{array}{l}\text { Banyak } \\
\text { ( } 21\end{array}$ & 0 & 0 & 0 \\
laporan) & & & \\
\hline
\end{tabular}

Tabel 5 Derajat keselamatan pasien menurut responden

\begin{tabular}{lccc}
\hline Kategori & $\begin{array}{l}\text { Puskesmas } \\
\text { Garuda } \\
\text { (n=24) }\end{array}$ & $\begin{array}{l}\text { Puskesmas } \\
\text { Ibrahim } \\
\text { Adjie } \\
\text { (n=22) }\end{array}$ & $\begin{array}{l}\text { Total } \\
(\mathbf{n}=46)\end{array}$ \\
\hline Sempurna & 0 & 0 & 0 \\
Sangat baik & 10 & 11 & 21 \\
Cukup & 14 & 11 & 25 \\
$\begin{array}{l}\text { Buruk dan } \\
\text { sangat } \\
\text { buruk }\end{array}$ & 0 & 0 & 0 \\
\hline
\end{tabular}

Data penelitian pada tabel 3 menunjukkan bahwa Puskesmas PONED di Kota Bandung memiliki tiga indikator yang masuk kategori kuat yaitu, "Pembelajaran yang terorganisir dan perkembangan yang berkelanjutan" (94\%); indikator "Kerja sama dalam satu unit" $(91 \%)$; dan indikator "Kerja sama antar unit" (85\%), enam indikator yang masuk kategori sedang yaitu "Harapan dan tindakan manajer dan supervisor dalam mempromosikan kesehatan" (58\%); "Keterbukaan dalam komunikasi" (53\%); "Unpam balik dan komunikasi tentang kesalahan" (62\%); "Dukungan manajemen terhadap keselamatan pasien" (69\%); "Handoff dan transisi" (65\%); dan "Persepsi keseluruhan terhadap keselamatan pasien" (61\%), dan tiga indikator yang masuk dalam kategori lemah yaitu, indikator "Frekuensi pelaporan kejadian" $(45 \%)$; indikator "Respons tidak menghukum terhadap pasien" (45\%); dan indikator "Staffing" (36\%).

Tabel 4 menunjukkan bahwa secara umum jumlah laporan insiden keselamatan pasien dalam satu tahun terakhir yang diisi dan dikumpulkan oleh responden masuk dalam kategori sedikit (1-5 laporan). Tabel 5 menunjukkan bahwa responden umumnya beranggapan bahwa derajat keselamatan pasien pada puskesmas dimana responden bekerja masuk dalam kategori cukup.

\section{Pembahasan}

Data penelitian menunjukkan bahwa indikator budaya keselamatan pasien pada Puskesmas PONED di Kota Bandung umumnya ada 
dalam kategori sedang. Hasil ini lebih baik dibandingkan dengan layanan kesehatan primer di Turki pada tahun 2009 yang indikator budaya keselamatan pasiennya kebanyakan masuk dalam kategori lemah15. Banyaknya indikator budaya keselamatan pasien pada Puskesmas PONED di Kota Bandung yang masuk kategori sedang juga sesuai dengan data yang menunjukkan bahwa derajat keselamatan pasien menurut sebagian besar responden masuk dalam kategori cukup.

Puskesmas PONED di Kota Bandung memiliki tiga indikator yang masuk dalam kategori lemah, yaitu indikator "Respons tidak menghukum terhadap pasien", indikator "Staffing", dan indikator "Frekuensi pelaporan kejadian". Ketiga indikator tersebut juga masuk dalam kategori lemah pada penelitian di pelayanan kesehatan primer di Turki. ${ }^{15}$ Pelayanan kesehatan primer di Turki memiliki empat indikator lain yang masuk dalam kategori lemah, yaitu indikator "Pembelajaran yang terorganisir dan perkembangan yang berkelanjutan"; indikator "Dukungan manajemen terhadap keselamatan pasien"; indikator "Keterbukaan dalam komunikasi"; dan indikator "Kerja sama antar unit”.

Indikator "Staffing" pada Puskesmas PONED di Kota Bandung memiliki respons positif sebesar $36 \%$, berarti hanya $36 \%$ responden yang berpendapat bahwa jumlah pegawai cukup untuk menangani beban kerja yang ada dan ada jam kerja yang sesuai untuk memberikan pelayanan yang terbaik kepada pasien. ${ }^{14}$ Nilai tersebut lebih rendah dibandingkan pelayanan kesehatan primer di Turki yang sebesar $49 \% .{ }^{15}$ Peryataan untuk menilai indikator tersebut adalah: "Jumlah karyawan cukup untuk menangani beban kerja yang ada di unit anda bekerja"; "Orang-orang bekerja melebihi batas waktu lama bekerja maksimum yang paling baik untuk keselamatan pasien"; "Karyawan sementara (seperti karyawan magang) yang ada di unit ini melebihi jumlah maksimum karyawan sementara yang paling baik untuk keselamatan pasien"; dan "Saat ini, unit ini ada dalam keadaan krisis dimana karyawan harus menyelesaikan sangat banyak pekerjaan dalam waktu singkat". Hal ini menunjukkan bahwa perlu ada peninjauan lebih jauh mengenai jumlah pegawai dan beban kerja di Puskesmas PONED di Kota Bandung.

Respons positif pada indikator "Respons tidak menghukum terhadap pasien" ada $45 \%$, berarti hanya $45 \%$ responden yang merasa tidak dipojokkan oleh kesalahan yang mereka lakukan. ${ }^{14}$ Nilai tersebut lebih tinggi dibandingkan dengan pelayanan kesehatan primer di Turki yang hanya $12 \% .^{15}$ Peryataan untuk menilai indikator tersebut adalah: "Karyawan merasa dipojokan jika melakukan kesalahan"; "Ketika suatu kejadian dilaporkan, rasanya seperti pelakunya yang dilaporkan bukan kesalahanya"; dan "Orang-orang di unit ini kuatir bahwa kesalahan yang mereka lakukan akan disimpan dalam data penilaian kerja mereka". Rendahnya respons positif pada indikator tersebut juga sesuai dengan rendahnya respons positif pada indikator "Frekuensi pelaporan kejadian".

Indikator "Frekuensi pelaporan kejadian" memiliki respons positif sebesar $45 . \%$, berarti hanya $45 \%$ responden yang merasa bahwa tipetipe kesalahan berikut dilaporkan, yaitu kesalahan yang ditemukan dan diperbaiki sebelum mempengaruhi pasien; kesalahan yang tidak berpontensi merugikan pasien; dan kesalahan dimana pasien tidak dirugikan walaupun seharusnya memiliki potensi untuk merugikan. ${ }^{14}$ Nilai tersebut lebih tinggi dibandingkan pelayanan kesehatan primer di Turki yang hanya 12\%. ${ }^{15}$ Pertanyaan untuk menilai indikator tersebut adalah: "Ketika terjadi kesalahan, tetapi kesalahan diketahui dan diperbaiki sebelum memberikan efek ke pasien, seberapa sering hal ini dilaporkan?"; "Ketika kesalahan dilakukan, tetapi tidak berpotensi merugikan pasien, seberapa sering hal ini dilaporkan?"; dan "Ketika kesalahan dilakukan sebenarnya dapat merugikan pasien, tetapi pada saat itu pasien tidak dirugikan, seberapa sering hal ini dilaporkan?" Secara umum laporan insiden keselamatan pasien dalam satu tahun terakhir yang diisi dan dikumpulkan oleh tenaga kesehatan masuk dalam kategori sedikit (1-5 laporan). Pada Puskesmas PONED di Kota Bandung hal ini mungkin disebabkan oleh tingginya budaya menyalahkan yang dibuktikan dengan lemahnya indikator budaya "Respons tidak menghukum terhadap pasien".

Keterbatasan penelitian. Kuesioner yang digunakan pada penelitian ini hanya memiliki satu indikator yang memenuhi kriteria uji validitas dan reliabilitas dengan nilai $r>0,3$ dan $\alpha>0,7$ yaitu indikator "Frekuensi pelaporan kejadian". Hal ini mungkin karena peneliti tidak menggunakan jasa penerjemah tersumpah. Terdapat enam Puskesmas PONED di Kota Bandung, namun penelitian ini hanya menilai budaya keselamatan pasien pada dua puskesmas PONED, yaitu UPT Puskesmas Garuda dan UPT Puskesmas Ibrahim Adjie, oleh karena itu belum dapat menggambarkan budaya keselamatan pasien pada seluruh Puskesmas PONED di Kota Bandung.

Simpulan dan saran. Puskesmas PONED di Kota Bandung memiliki budaya keselamatan pasien yang dalam kategori sedang. Terdapat tiga indikator budaya keselamatan pasien yang dalam kategori lemah, yaitu "Respons tidak menghukum terhadap kesalahan", "Staffing" dan "Frekuensi 
pelaporan kejadian". Indikator "Staffing" yang masuk kategori lemah menunjukkan bahwa perlu ada peninjauan terhadap jumlah pegawai dan beban kerja di Puskesmas PONED di Kota Bandung. Lemahnya indikator "Respons tidak menghukum terhadap kesalahan" dan "Frekuensi pelaporan kejadian" menunjukkan bahwa faktor budayalah yang menyebabkan laporan insiden keselamatan pasien di Puskesmas PONED sedikit. Penelitian mengenai budaya keselamatan pasien di Puskesmas PONED sebaiknya lebih dikembangkan dan dibuat alat ukur untuk menilai budaya keselamatan pasien di Puskesmas PONED. Peneliti juga menyarankan agar kedepannya penelitian dilakukan dengan jumlah Puskesmas PONED yang lebih banyak.

\section{Daftar Pustaka}

1. Hennessy JL, Hughes F. Appreciative inquiry: $A$ research tool for mental health services. Journal of psychosocial nursing and mental health services. 2014;52(6):34-40.

2. Wahyudi YP, Nurfaidah S. Pengelolaan Rujukan Kedaruratan Maternal di Rumah Sakit dengan Pelayanan PONEK. Jurnal Kedokteran Brawijaya. 2014;28(1):84-8.

3. Andel C, Davidow SL, Hollander M, Moreno DA. The economics of health care quality and medical errors. Journal of health care finance. 2012;39(1):39.

4. Qoomerah SN, Lidiyah U, A. Hubungan Faktor Komunikasi dengan Insiden Keselamatan Pasien. Journal of Ners Community. 2016;6:166-74. Epub November 2016.

5. James JT. A new, evidence-based estimate of patient harms associated with hospital care. Journal of patient safety. 2013;9(3):122-8.

6. Iriviranty A, Ayuningtyas D, Misnaniarti M. Evaluation of Patient Safety Culture and Organizational Culture as a Step in Patient Safety Improvement in a Hospital in Jakarta, Indonesia. Journal of Patient Safety \&
Quality Improvement. 2016;4(3):394-9.

7. Aranaz-Andres JM, Aibar C, Limon R, Mira JJ, Vitaller J, Agra Y, et al. A Study of The Prevalence of Adverse Events in Primary Healthcare in Spain. European journal of public health. 2012;22(6):921-5. Epub 2012/11/28.

8. Adams RJ, Tucker G, Price K, Hill CL, Appleton SL, Wilson DH, et al. Self-reported adverse events in health care that cause harm: a population-based survey. Medical Journal of Australia. 2009;190(9):484.

9. Wang X, Liu K, You LM, Xiang JG, Hu HG, Zhang LF, et al. The Relationship between Patient Safety Culture and Adverse Events: a Questionnaire Survey. International journal of nursing studies. 2014;51(8):1114-22. Epub 2014/01/15.

10. Huang DT, Clermont G, Kong L, Weissfeld LA, Sexton JB, Rowan KM, et al. Intensive Care Unit Safety Culture and Outcomes: a US Multicenter Study. International Journal for Quality in Health Care. 2010;22(3):15161.

11. Mardon RE, Khanna K, Sorra J, Dyer $\mathrm{N}$, Famolaro T. Exploring relationships between hospital patient safety culture and adverse events. Journal of patient safety. 2010;6(4):226-32.

12. Kusek L. Preventing central line-associated bloodstream infections. Journal of nursing care quality. 2012;27(4):283-7.

13. Kamenkes. Pedoman Penyelenggaraan Puskesmas Mampu PONED. Jakarta: Kementerian Kesehatan RI. 2013.

14. Cramer ME, Jones KJ, Hertzog M. Nurse staffing in critical access hospitals: Structural factors linked to quality care. Journal of nursing care quality. 2011;26(4):335-43.

15. Bodour S, Fliz E. A survey on patient safety culture in primary healthcare services in Turkey. International Journal for Quality in Health Care 2009. 2009;21(Number 5):34855. 